\title{
Suppression of Oxygen Reduction Reaction Activity on Pt-based Electrocatalysts
}

\section{from Ionomer Incorporation}

\author{
Kazuma Shinozaki ${ }^{\mathrm{a}}$ b, c, *, Yu Morimoto ${ }^{\mathrm{c}}$, Bryan S. Pivovar ${ }^{\mathrm{a}}$ and Shyam S. Kocha ${ }^{\mathrm{a}}$ \\ ${ }^{a}$ National Renewable Energy Laboratory, Electrochemical Characterization Labs, Golden, CO \\ 80401, USA \\ ${ }^{b}$ Colorado School of Mines - Department of Chemistry, Golden, CO 80401, USA \\ ${ }^{c}$ Toyota Central R\&D Labs., Inc., Aichi, 480-1192 Japan \\ *Corresponding author email: Shinozaki@mosk.tytlabs.co.jp
}


The impact of Nafion on the oxygen reduction reaction (ORR) activity is studied for $\mathrm{Pt} / \mathrm{C}$ and Pt-alloy/C catalysts using thin-film rotating disk electrode (TF-RDE) methods in $0.1 \mathrm{M} \mathrm{HClO}_{4}$. Ultrathin uniform catalyst layers and standardized activity measurement protocols are employed to obtain accurate and reproducible ORR activity. Nafion lowers the ORR activity which plateaus with increasing loading on Pt catalysts. Pt particle size is found not to have significant influence on the extent of the SA decrease upon Nafion incorporation. Catalysts using high surface area carbon (HSC) support exhibits attenuated activity loss resulting from lower ionomer coverage on catalyst particles located within the deep pores. The impact of metallic composition on the activity loss due to Nafion incorporation is also discussed.

Keywords

Oxygen reduction reaction; Platinum; Platinum Alloy; Nafion ionomer; Rotating disk electrode method; Ionomer coverage 


\section{Introduction}

Automotive manufacturers have recently started launching proton exchange membrane fuel cell (PEMFC) vehicles in a small scale (1000 vehicles/year production). For successful commercialization, a further reduction of Pt catalyst usage from $\sim 30 \mathrm{~g}$ to $\sim 10 \mathrm{~g}\left(100 \mathrm{~kW}_{\text {stack }}\right)$ is necessary [1-3]. The Pt loading can be reduced by employing novel higher activity catalysts, improving the Pt utilization, and optimizing the cathode catalyst layer.

Ionomers such as Nafion are commonly incorporated into catalyst layers of PEMFCs to provide protonic pathways for efficient platinum utilization [4]; it is well-known that excessive ionomer can block the pores in the catalyst layer and sub-optimal levels can lead to increase catalyst layer resistance and lower performance. Even for catalyst layers with optimal ionomer-to-carbon (I/C) weight ratios, recent studies using low platinum loading PEMFCs suggest that fuel cell performance at high current density is partly limited by $\mathrm{O}_{2}$ transport through Pt/ionomer interface [5-12]. Fundamental studies using RDE methods also indicate that Nafion lowers the oxygen reduction reaction (ORR) activity on single crystalline, polycrystalline $\mathrm{Pt}$ and $\mathrm{Pt}$ alloy surfaces and nanostructured thin film (3M NSTF) [13-17]. In these studies, thin films (10's of $\mathrm{nm}$ ) were applied to the electrode surfaces by capping with Nafion ionomer. A 
positive shift on the onset potential for $\mathrm{OH}$ and other oxide species formation and a suppression of the ORR activity are typically observed after capping with Nafion. Subbaraman et al. [13] attributed the features observed on cyclic voltammograms under inert atmosphere to sulfonate anion adsorption on Pt surfaces using a CO displacement method [18]. Moreover, the \% ORR activity loss on Nafion-capped Pt (hkl) in perchloric acid solution (weakly-adsorbing anions) was found to follow the same order, Pt $(111)>(110)>(100)$, as that on Nafion-free surfaces in sulfuric acid; this fact led them to conclude that sulfonate anion adsorption was the main cause for lowered ORR activity. In contrast to these detailed kinetics studies on well-defined bulk Pt surfaces, little work has been reported on practical carbon supported nanoparticle platinum $(\mathrm{Pt} / \mathrm{C})$ catalysts $[14,19-21]$. The lack of studies is first of all due to the fact that the ionomer cannot be simply eliminated from PEMFCs since the ionomer is crucial and indispensable for providing facile protonic pathways. However, ionomer is not necessary as a proton conducting component in half cell studies in acid electrolyte. The early work of Guilminot et al. [22] used ultramicroelectrodes with cavity technique and demonstrated that the presence of Nafion alters the ORR activity of a $\mathrm{Pt} / \mathrm{C}$ catalyst by employing catalyst layers with and without recast Nafion. In contrast, Studies using thin film RDE (TF-RDE) methods have not been applied traditionally because of the 
following actual and perceived difficulties: (i) elimination of ionomer can result in a low ink dispersion and poor catalyst film quality — uncontrolled catalyst mass on glassy carbon (GC) substrates and limited $\mathrm{O}_{2}$ diffusion within catalyst layer (ii) catalysts can detach from GC substrate surfaces during experiments without ionomer adhesion — uncontrolled catalyst mass on GC substrates [23].

In our previous study, we reported that the use of extremely thin and uniform films is indispensable to the kinetics study of ORR catalysts without hindrance from $\mathrm{O}_{2}$ diffusion limitations within the catalyst layer, and demonstrated that ionomer is not essential to obtain well-dispersed stable thin catalyst films with extremely high ORR activity [24]. The impact of ionomer on the ORR activity can now be studied using the Nafion-free thin uniform catalyst layers and Nafion capped catalyst layers using the pre-formed Nafion-free catalyst layers.

In this work, we present results on the effect of Nafion ionomer on the ORR activity as well as $\mathrm{CVs}$ under inert atmosphere for several commercial $\mathrm{Pt} / \mathrm{C}$ and $\mathrm{Pt}$-alloy/C catalysts using a TF-RDE method by employing thin-uniform catalyst layers obtained with advanced catalyst layer fabrication techniques [24].

\section{Experimental}




\subsection{Catalysts, chemicals and reactant gases.}

$\mathrm{Pt} / \mathrm{C}$ and Pt-alloy/C catalysts employed in this study were manufactured by Tanaka Kikinzoku Kyogyo (TKK, Japan) and Umicore (Germany), and the detailed specifications along with the nomenclature for the catalysts are listed in Table 1. Surface area obtained from $\mathrm{CO}$ chemisorption and crystallite size from XRD were provided by the manufacturer. Bulk poly-Pt $\left(\phi=5 \mathrm{~mm}, 0.196 \mathrm{~cm}^{2}\right.$, embedded in a PTFE cylinder, Pine Instruments) were employed in RDE measurements. Deionized (DI) water $(>18.2 \mathrm{M} \Omega \cdot \mathrm{cm}$, TOC $<5 \mathrm{ppb})$ from a Milli Q system (Millipore) was used for acid dilutions and glassware cleaning. The following chemicals were used in electrolyte preparation and ink formulation: isopropanol (IPA, CHROMASOLV ${ }^{\circledR}$ Plus, for HPLC, 99.9\%, Sigma-Aldrich), non-ionic surfactant (Triton X-100, Sigma, \#T-9284), Nafion solution (DE520, EW1000, $5 \mathrm{wt} \%, 0.924 \mathrm{~g} \cdot \mathrm{mL}^{-1}$, Sigma-Aldrich), $0.05 \mu \mathrm{m}$ alumina dispersion (Buehler Inc.), concentrated (conc.) sulfuric acid (Certified ACS Plus, Fisher Scientific), Nochromix ${ }^{\circledR}$ (Godax Laboratories, Inc.), and 70\% perchloric acid Veritas ${ }^{\circledR}$ Doubly Distilled (GFS chemicals). $70 \% \mathrm{HClO}_{4}$ were diluted with DI water to prepare $0.1 \mathrm{M} \mathrm{HClO}_{4}$ electrolyte. All electrochemical measurements were carried out in $0.1 \mathrm{M} \mathrm{HClO}_{4}$. Gases used in this study were all classified as 
ultrapure grade $\left(\mathrm{N}_{2}, 99.9999 \%, \mathrm{H}_{2}, 99.999 \%, \mathrm{O}_{2}, 99.9999 \%, \mathrm{CO} 99.998 \%\right.$ Matheson Gas).

Table 1. Electrocatalyst specifications.

\begin{tabular}{|c|c|c|c|c|c|c|}
\hline Supplier & $\begin{array}{c}\text { Pt Metal } \\
\text { content } \\
\text { (wt\%) }\end{array}$ & Carbon & $\begin{array}{l}\text { Nomenclature } \\
\text { for this work }\end{array}$ & $\begin{array}{c}\text { Supplier } \\
\text { nomenclature }\end{array}$ & $\begin{array}{l}\text { Surface } \\
\text { Area Co } \\
\left(\mathrm{m}^{2} \cdot \mathrm{g}^{-1}\right)\end{array}$ & $\begin{array}{l}\text { Crystallite } \\
\text { size } \\
\text { XRD (nm) }\end{array}$ \\
\hline TKK & 26.1 Pt & HSC & $\mathrm{Pt} / \mathrm{HSC}$ & NA & 271 & 1.8 \\
\hline TKK & 46.4 Pt & HSC & $\mathrm{Pt} / \mathrm{HSC}$ & TEC10E50E & 132.6 & 2.6 \\
\hline TKK & $29 \mathrm{Pt}$ & Vulcan & $\mathrm{Pt} / \mathrm{V}$ & TEC10V30E & 157.3 & 2.5 \\
\hline TKK & 46.4 Pt & Vulcan & $\mathrm{Pt} / \mathrm{V}$ & TEC10V50E & 77.6 & 2.5 \\
\hline Umicore & $20 \mathrm{Pt}$ & $\begin{array}{c}\text { Low Surface Area } \\
\text { Carbon (LSC) }\end{array}$ & Pt/LSC & Elyst Pt20 0380 & NA & $3.0-3.5$ \\
\hline Umicore & $48 \mathrm{Pt}$ & LSC & $\mathrm{Pt} / \mathrm{LSC}$ & Elyst Pt50 0380 & NA & $3.6-4.2$ \\
\hline TKK & $\begin{array}{l}\text { Pt:Co }= \\
46.4: 5.0\end{array}$ & HSC & $\mathrm{Pt}_{3} \mathrm{Co} / \mathrm{HSC}$ & TEC36E52 & 351 & 3.9 \\
\hline TKK & $\begin{array}{l}\text { Pt:Co:Mn = } \\
\text { 46.9:3.4:1.2 }\end{array}$ & HSC & $\mathrm{PtCoMn} / \mathrm{HSC}$ & NA & 98.0 & NA \\
\hline Umicore & $\begin{array}{l}\mathrm{Pt}: \mathrm{Co}= \\
27.4: 2.6\end{array}$ & HSC & $\mathrm{Pt}_{3} \mathrm{Co} / \mathrm{HSC}$ & Elyst Pt30 0670 & NA & $4.0-4.5$ \\
\hline
\end{tabular}

\subsection{Instrumentation.}

A microbalance (UMX2, Mettler Toredo), bath sonicator (FS30H, Fisher Scientific, output: $42 \mathrm{kHz}, 100 \mathrm{~W}$ ) and horn sonicator (S-4000, QsonICA, LLC., output: $20 \mathrm{kHz}$, $600 \mathrm{~W}$ max) were employed in the preparation of catalyst inks. Autolab PGSTAT302N potentiostat operated with NOVA software from Metrohm was used to obtain cyclic 
voltammograms (CVs) and ORR current-potential (I-E) curves, and to apply $i R$ correction during $\mathrm{CV}$ and $I-E$ curve measurements. RDE Rotators, PTFE rotator shafts and GC tips ( $\phi=5 \mathrm{~mm}, 0.196 \mathrm{~cm}^{2}$, embedded in a PTFE cylinder) were obtained from Pine Instruments. An optical microscope (AM4815ZT Dino-Lite Edge, Dino-Lite Digital Microscope) was routinely used to facilitate inspection of catalyst layers on GC. A JEOL JSM-7000F Field Emission Microscope was employed to obtain SEM images.

\subsection{Electrochemical cell setup.}

The electrochemical cell design $(130 \mathrm{~mL}$; counter electrode: Pt gauze; reference electrode: RHE; working electrode: poly-Pt or GC with catalyst layer) as well as detailed cleaning procedure are described in our previous work [25]. The electrochemical cell was meticulously cleaned as described in detail in our previous work [25]. The GC and poly-Pt RDE tips were polished using $0.05 \mu \mathrm{m}$ alumina slurry before each experiment as described in detail in our previous work [24, 25].

\subsection{Standardized electrochemical measurement protocols.}

Protocols for conditioning, $\mathrm{CV}$ s for electrochemical area (ECA) estimation and ORR I-E curve measurements established on the basis of our comprehensive experimental 
studies have been meticulously adhered to in this manuscript and we briefly state these measurement protocols [24-26]. For conditioning, potential cycling was conducted in the range $0.025-1.2 \mathrm{~V}$ at $500 \mathrm{mV} \cdot \mathrm{s}^{-1}$ for $50-100$ cycles. $\mathrm{H}_{\mathrm{UPD}}$ charge was obtained from $\mathrm{H}$ adsorption current observed between $\sim 0.05 \mathrm{~V}$ (inflection point) and $\sim 0.4 \mathrm{~V}$ (double layer region) in the third cycle of $\mathrm{CV}$ measured in $0.025-1.0 \mathrm{~V}$ at $20 \mathrm{mV} \cdot \mathrm{s}^{-1}$ under $\mathrm{N}_{2}$ atmosphere and ECA was estimated using $210 \mu \mathrm{C} \cdot \mathrm{cm}^{-2}$ Pt [27-30]. ORR I-E curve was measured from -0.01 to $1.0 \mathrm{~V}$ at $20 \mathrm{mV} \cdot \mathrm{s}^{-1}$ and $1600 \mathrm{rpm}$ under $\mathrm{O}_{2}$ atmosphere. Correction for background (b.g.) currents was applied to all ORR I-E curves measured with in-situ correction of solution resistance $\left(R_{\text {soln }}\right)$. All measurements were conducted at $23 \pm 2{ }^{\circ} \mathrm{C}$. ORR kinetic currents have been corrected to $100 \mathrm{kPa} \mathrm{O}_{2}$ and Koutecký-Levich equation was applied to correct for $\mathrm{O}_{2}$ diffusion in electrolyte solution to obtain the SA $\left(\mathrm{mA} \cdot \mathrm{cm}^{-2}\right)$ and MA $\left(\mathrm{mA} \cdot \mathrm{mg}^{-1} \mathrm{Pt}\right)$. The SA and MA are reported at 0.9 V vs. RHE in this manuscript.

\subsection{Catalyst layer fabrication.}

Various fabrication techniques reported in our previous studies were applied for each catalyst to find a suitable technique for each catalyst to reproducibly obtain thin-uniform catalyst layers. Because such a suitable technique depends on catalysts, 
employed techniques are described for each catalyst. For a TKK Pt/HSC (TEC10E50E), all the techniques can provide thin-uniform catalyst layers. Although one of the techniques described below incorporates slight amount of Nafion in the ink, obtained catalyst layers for the Pt/HSC exhibit as high activity values as catalyst layers fabricated using the other two techniques as reported in our previous studies [24, 31]. Therefore, we treat activity values obtained using the fabrication technique with an inclusion of slight amount of Nafion as Nafion-free activity values. We note that some of the catalyst layers fabricated using the techniques still have thin $(\sim 10 \mu \mathrm{m}$-wide $)$ coffee ring structure on the periphery of GC substrates [24]. Therefore, we estimated effective (vol\% weighted) thickness from thickness of catalyst layer on periphery and on the rest of GC area and vol\% of catalysts located on the two area $[24,26]$.

For TKK Pt/HSC (TEC10E50E) and Pt/V catalysts, catalyst inks were prepared by mixing Pt/C catalyst powder with $7.6 \mathrm{~mL}$ DI water and $2.4 \mathrm{~mL}$ IPA, and sonicating in the ice-water bath sonicator (10 $\mathrm{min})$ followed by sonication using the horn sonicator ( 6 $\mathrm{W}, 30 \mathrm{~s}$ ) with sample vial placed in an ice-water bath. A $5 \mu \mathrm{L}$ aliquot of the catalyst ink (3-4.5 $\mu \mathrm{g}_{\mathrm{Pt}} \cdot \mathrm{cm}^{-2}$ ) was pipetted onto the polished GC tip placed on a custom-built stainless steel holder and positioned in a beaker $(400 \mathrm{~mL})$ filled with $5 \mathrm{~mL}$ of IPA. The beaker was sealed with a polymer film that was perforated. The beaker with the 
electrodes and IPA were placed in an oven heated to $40^{\circ} \mathrm{C}$ to gradually ( $\sim 3$ hours) dry the inks under IPA vapor $(\sim 13 \mathrm{kPa})$ and form the catalyst layer $[19,24]$. The estimated effective thickness was $0.7 \mu \mathrm{m}$ for a $46 \mathrm{wt} \% \mathrm{Pt} / \mathrm{HSC}$ catalyst layer, and $0.4 \mu \mathrm{m}$ for a 46 $\mathrm{wt} \% \mathrm{Pt} / \mathrm{V}$ catalyst layer.

For $\mathrm{TKK} \mathrm{Pt}_{3} \mathrm{Co} / \mathrm{HSC}$, catalyst inks were prepared by mixing the catalyst powder with 7.6 mL DI water, $2.4 \mathrm{~mL}$ IPA and $2.5 \mu \mathrm{L}$ of 10 times diluted TRITON X-100 with DI water, and sonicating with the same procedure as applied for other catalysts [24]. A 2.5 $\mu \mathrm{L}$ aliquot of the catalyst ink $\left(4.5 \mu \mathrm{g}_{\mathrm{Pt}} \cdot \mathrm{cm}^{-2}\right)$ was pipetted onto the polished GC tip placed on a custom-built stainless steel holder and placed in an oven heated to $40^{\circ} \mathrm{C}$ to dry under the inks under air atmosphere.

For the other Pt/C and Pt-alloy/HSC catalysts, catalyst inks were prepared by mixing Pt/C catalyst powder with $7.6 \mathrm{~mL}$ DI water, $2.4 \mathrm{~mL}$ IPA and 10 times diluted Nafion IPA solution with ionomer to carbon ratio: $\mathrm{I} / \mathrm{C}=0.008$ for Umicore $\mathrm{Pt} / \mathrm{C}, 0.04$ for TKK $\mathrm{PtCoMn} / \mathrm{C}$ and Umicore $\mathrm{PtCo} / \mathrm{HSC}$, and sonicating with the same procedure as applied for other catalysts. A $10 \mu \mathrm{L}$ aliquot of the catalyst ink $\left(3-9 \mu \mathrm{g}_{\mathrm{Pt}} \cdot \mathrm{cm}^{-2}\right)$ was pipetted onto the polished GC tip on an inverted rotator shaft at $100 \mathrm{rpm}$. The ink was subsequently dried under ambient conditions by increasing and maintaining the rotator speed at 700 
rpm for a period of $15 \min [24,32]$. The estimated effective thickness was $1.0 \mu \mathrm{m}$ for a $46 \mathrm{wt} \% \mathrm{Pt} / \mathrm{HSC}$ catalyst layer.

\subsection{Nafion caps on poly-Pt and Pt/HSC.}

Subsequent to an ORR activity evaluation on bare poly-Pt, the electrode was rinsed, covered with DI water and soaked in $1 \mathrm{mM} \mathrm{KBr}$ aqueous solution for $15 \mathrm{sec}$ [16]; on rinsing with DI water, the poly-Pt surface was observed to become hydrophobic. A $2 \mu \mathrm{L}$ aliquot of $0.025 \mathrm{wt} \%$ Nafion solution (x200 diluted with IPA) was dropped on poly-Pt surface with the electrode dried at $23^{\circ} \mathrm{C}$ followed by annealing in an oven at $140^{\circ} \mathrm{C}$ for 15 min to increase physicochemical stability $[13,17]$. Alternatively, direct application of Nafion solution on bare poly-Pt surface $\left(\mathrm{N}_{2}\right.$-dried, DI water rinsed) followed by the identical annealing process also produced the same results. For the case of $\mathrm{Pt} / \mathrm{C}$ and Pt-alloy/C catalysts, diluted Nafion solution $(2.5 \mu \mathrm{L})$ was dropped on the films followed by drying at $23^{\circ} \mathrm{C}$. On the basis of limited analysis of Nafion capped Pt/C catalyst layers using SEM, Nafion seems to penetrate through the entire thickness of catalyst layer; we observed materials that were burnt by electron beam during SEM analysis through the entire catalyst layer thickness direction after Nafion capping. I/C ratio in the range 0.5-3.0 were obtained for a given electrode through a series of steps involving 
measurement of ORR I-E, capping and drying. The entire sequence was repeated for up to 8 independent samples. The films were visually inspected for integrity before and after Nafion capping.

\section{Results and Discussion}

\subsection{Impact of Nafion on poly-Pt}

Before conducting a detailed investigation on the effect of ionomer on the ORR activity of Pt/C and Pt-alloy/C, we verified and reproduced the results presented in literature for the simpler poly-Pt system [13, 33-35]. The electrochemically conditioned poly-Pt was either capped directly with ionomer or after pre-soaking in a $\mathrm{KBr}$ solution to produce similar results. Figure 1a captures the effects ascribable to the ionomer on CVs under $\mathrm{N}_{2}$ and Fig. $1 \mathrm{~b}$ and the inset on ORR I-E curves. A negative shift in the onset of $\mathrm{H}_{\mathrm{UPD}}$ current and new peaks that manifest at $0.15 \mathrm{~V}$ (cathodic peak) and $0.18 \mathrm{~V}$ (anodic peak) are observed in Fig. 1a in close qualitative agreement with literature [13, 33-35]; Small differences on CVs between our study and the literature studies probably stem from a number of artifacts including the cleaning process of the poly-Pt surface, viz., electrochemical cleaning/inductive heating, type of Nafion ionomer, solvent used to dilute the ionomer, thickness of the ionomer film and its heat treatment. The $\mathrm{H}_{\text {UPD }}$ area 
decreased (by 2\%) from Nafion capping accompanied by slight shifts on the onset potential of oxide formation/reduction regime.

In Fig. 1b, Nafion-capped surface exhibits reduced current density in diffusion regime from $\sim 0.7 \mathrm{~V}$ to $\sim 0.3 \mathrm{~V}$. This is likely because of the anion adsorption. Recent PEMFC studies showed that a Nafion thin film has a large interfacial $\mathrm{O}_{2}$ transport resistance $[9,12]$ and that large interfacial $\mathrm{O}_{2}$ transport resistance was shown to stem from a very thin high density ionomer layer formed on ionomer/Pt interface by MD studies by Jinnouchi et al. [11].

Precipitous ORR activity losses were observed accompanied by a potential dependent shift of the entire curve (Fig. 1b, inset): $\sim 60 \%$ loss at $0.95 \mathrm{~V}, \sim 70 \%$ loss at $0.9 \mathrm{~V}$ (from $2.8 \mathrm{~mA} \cdot \mathrm{cm}^{-2}{ }_{\mathrm{Pt}}$ to $0.80 \mathrm{~mA} \cdot \mathrm{cm}^{-2}$ Pt), $\sim 80 \%$ loss at $0.8 \mathrm{~V}$. Recent fundamental studies using well-defined catalyst surfaces reported that sulfonate adsorption is the main source that lowers the ORR activity [13-17]. Since anion species adsorb more strongly at higher potentials, one might expect to observe larger \%difference in activity at higher potentials originating from growing sulfonate coverage between Tafel curves for bare and Nafion-coated Pt surfaces. However, in the inset of Fig. 1b, the \%loss of activity with Nafion capping on poly-Pt is larger at lower potentials. This is likely because, at higher potential, the anion coverage is reduced by the growth of oxide [17]. 
The difference in extents of the onset potential shift on CVs under $\mathrm{N}_{2}$ and the shift in the Tafel plot appears to indicate different sensitivities for the effect of Nafion.
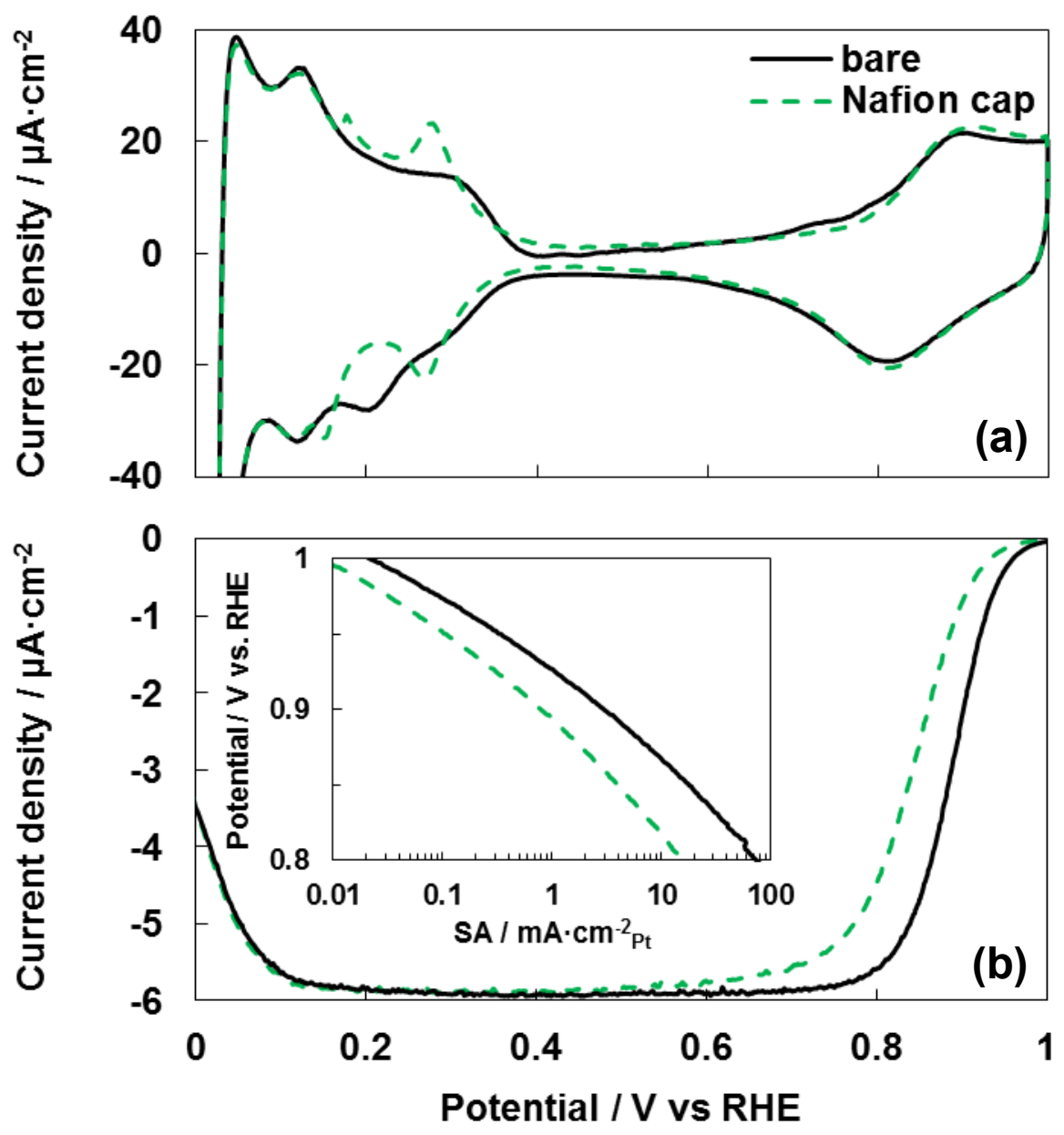

Figure 1. (a) CVs under $\mathrm{N}_{2}$ and (b) ORR I-E curves (inset: Tafel plot) in $0.1 \mathrm{M} \mathrm{HClO}_{4}$ at $20 \mathrm{mV} \cdot \mathrm{s}^{-1}$ for poly-Pt with and without Nafion cap. 


\subsection{Impact of Nafion on Pt-based catalysts on various carbon black supports}

High surface area carbon blacks (HSC) such as Ketjen Black have micropores within which $>50 \%$ of the Pt nanoparticles reside [36-39]; on the other hand, low surface area supports (LSC) such as Vulcan or graphitized carbons lack micropores so that most of the Pt particles are on the outer surface. CVs under $\mathrm{N}_{2}$ and ORR Tafel plots for $46 \mathrm{wt} \% \mathrm{Pt} / \mathrm{HSC}$ and $48 \mathrm{wt} \% \mathrm{Pt} / \mathrm{LSC}$ are shown in Fig. 2a-2d as examples to illustrate two extreme cases of supports. In Fig. 2a, 46 wt\% Pt/HSC exhibits neither peak shifts in $\mathrm{H}_{\mathrm{UPD}}$ region as is observed for poly-Pt nor onset potential shifts in oxide formation/reduction region. Correspondingly, in Fig. 2b, shifts in the ORR Tafel curves are not clearly observable until $\mathrm{I} / \mathrm{C}$ ratio becomes high ( $\mathrm{I} / \mathrm{C} \geq 1.5)$. In contrast, in Fig. $2 \mathrm{c}$, $48 \mathrm{wt} \% \mathrm{Pt} / \mathrm{LSC}$ exhibits observable peak shifts in $\mathrm{H}_{\mathrm{UPD}}$ region and slight shift on the onset potential of oxide formation regime with increasing $\mathrm{I} / \mathrm{C}$ ratio as is observed for poly-Pt. In the ORR Tafel curves (Fig. 2d), larger shifts are observed with increasing $\mathrm{I} / \mathrm{C}$ ratio and the extent of the shift at the highest $\mathrm{I} / \mathrm{C}$ ratio is similar to the shift observed for poly-Pt (the inset of Fig. 1b). In contrast to the observable potential dependence of \%loss in activity for poly-Pt surfaces as depicted in 3.1., such dependence was not observed for Pt/C catalysts. 

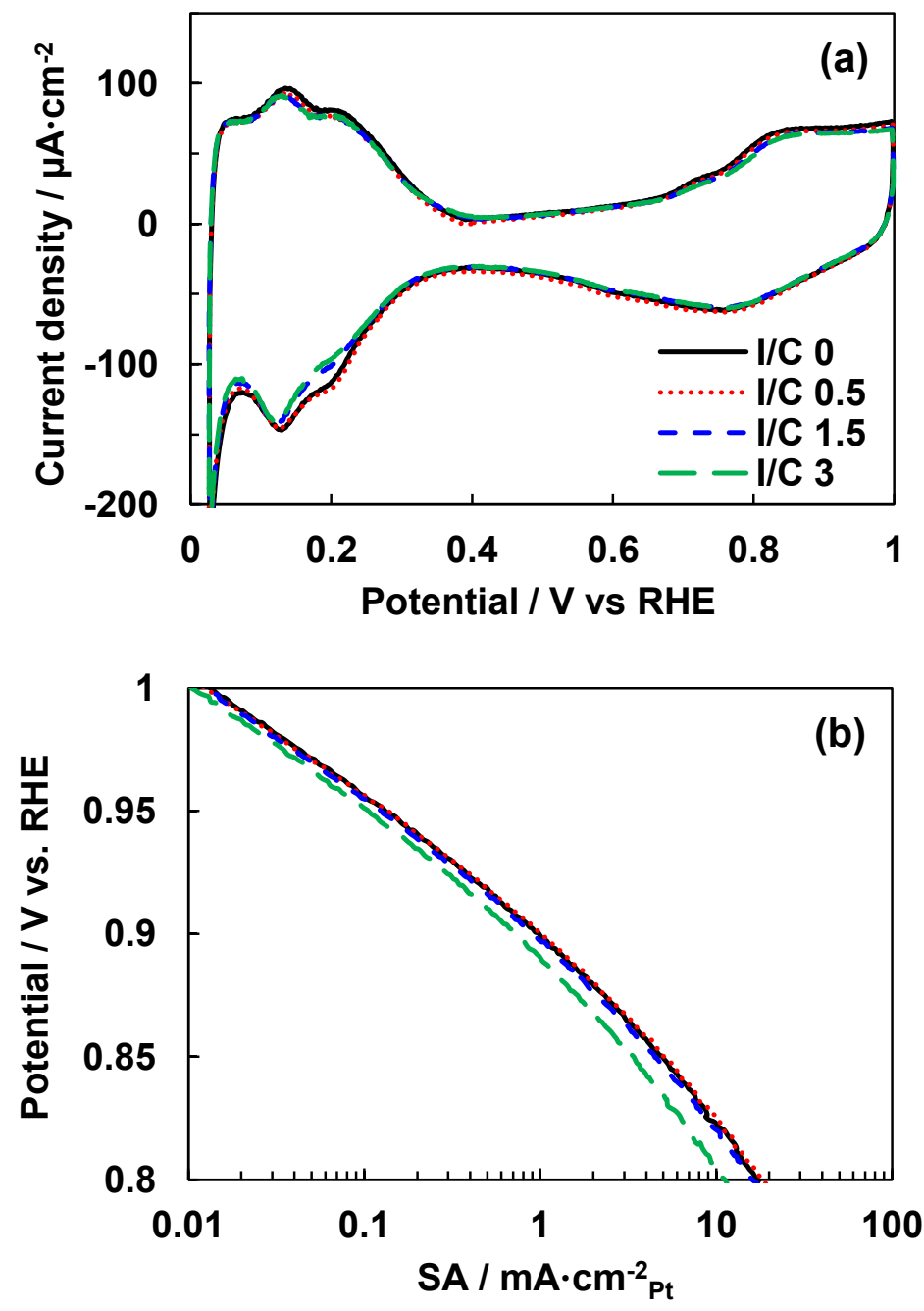

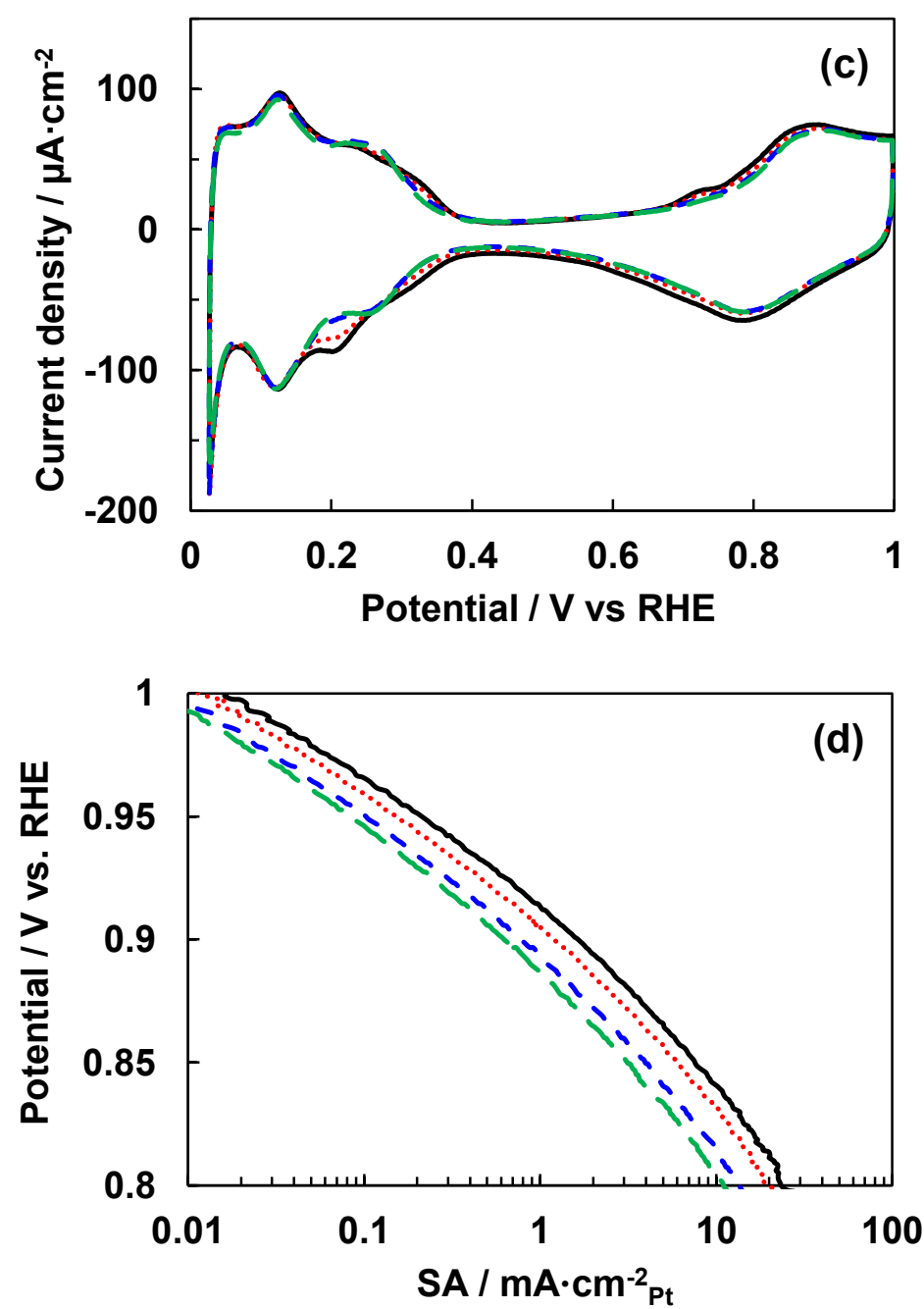

Figure 2. The effect of $I / C$ ratio on $(a, c) C V s$ under $\mathrm{N}_{2}$ and $(b, d)$ ORR $I-E$ curves in $0.1 \mathrm{M} \mathrm{HClO}_{4}$ at $20 \mathrm{mV} \cdot \mathrm{s}^{-1}$ for $(\mathrm{a}, \mathrm{b}) 46 \mathrm{wt} \% \mathrm{Pt} / \mathrm{HSC}$ and (c, d) $48 \mathrm{wt} \% \mathrm{Pt} / \mathrm{LSC}$.

To illustrate the effect of Nafion on SA at $0.9 \mathrm{~V}$ for various $\mathrm{Pt} / \mathrm{C}$ catalysts, the $\mathrm{SA}$ is plotted against I/C ratio in Fig. 3. The SA and MA can also be found in Tables 2 (I/C $\sim 0)$ and 3 (I/C dependence). At I/C ratio $\sim 0$ (Nafion-free), the SA varies depending on average Pt particle size/ECA as reported in our previous study [31]. When a Nafion cap 
is applied, the SA decreases for all catalysts in proportion to the $\mathrm{I} / \mathrm{C}$ ratio. In most cases above certain I/C ratio, the SA plateaus. Since the addition of ionomer either increases the thickness in a uniform manner or increases the coverage of Nafion agglomerates as reported in literature, the plateau seems to indicate that either a threshold thickness or maximum coverage is reached. The implication of the plateau will be discussed to more detail later in this section.

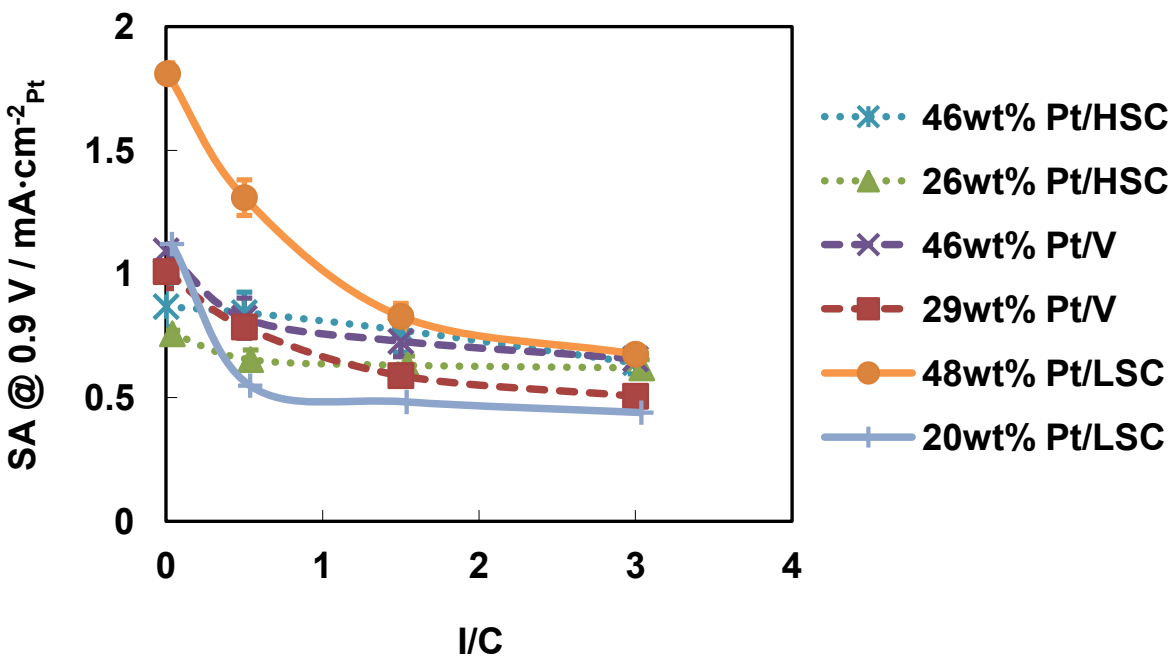

Figure 3. I/C ratio dependence of $\mathrm{SA}$ at $0.9 \mathrm{~V}$ for various $\mathrm{Pt} / \mathrm{C}$ catalysts. Error bars indicate standard deviation for catalysts tested using 4 or more samples (46 wt $\%$ and 26 wt $\% \mathrm{Pt} / \mathrm{HSC}, 29 \mathrm{wt} \% \mathrm{Pt} / \mathrm{V}$ and $48 \mathrm{wt} \% \mathrm{Pt} / \mathrm{LSC})$, and maximum and minimum for catalysts tested using less than 4 samples (46 wt\% Pt/V). 
Table 2. ECA, SA and MA at $0.9 \mathrm{~V}$ vs. RHE for Pt based catalysts at I/C $\sim 0$.

\begin{tabular}{|c|c|c|c|c|c|}
\hline Catalyst & \# of samples & $\operatorname{ECA}\left(m^{2} \cdot g^{-1}\right)$ & $\mathrm{SA}\left(\mathrm{mA} \cdot \mathrm{cm}^{-2} \mathrm{Pt}\right)$ & $\mathrm{MA}\left(\mathrm{mA} \cdot \mathrm{mg}^{-1} \mathrm{Pt}\right)$ & Reference \\
\hline $26.1 w t \% \mathrm{Pt} / \mathrm{HSC}$ & 6 & $136 \pm 3$ & $0.74 \pm 0.03$ & $1.01 \pm 0.05$ & [31] \\
\hline $46.4 \mathrm{wt} \% \mathrm{Pt} / \mathrm{HSC}$ & 44 & $101 \pm 7$ & $0.89 \pm 0.06$ & $0.90 \pm 0.09$ & [24] \\
\hline $29 w t \% \mathrm{Pt} / \mathrm{V}$ & 6 & $93.5 \pm 0.9$ & $1.01 \pm 0.06$ & $0.94 \pm 0.06$ & [31] \\
\hline 46.4wt\% Pt/V & 20 & $63 \pm 3$ & $1.12 \pm 0.07$ & $0.71 \pm 0.04$ & [24] \\
\hline $20 w t \% \mathrm{Pt} / \mathrm{LSC}$ & 8 & $66.4 \pm 0.8$ & $1.13 \pm 0.03$ & $0.75 \pm 0.02$ & [31] \\
\hline $48 w t \% \mathrm{Pt} / \mathrm{LSC}$ & 6 & $48.0 \pm 0.3$ & $1.79 \pm 0.05$ & $0.86 \pm 0.02$ & [31] \\
\hline 46.4 Ptwt\% $\mathrm{Pt}_{3} \mathrm{Co} / \mathrm{HSC}$ & 17 & $54 \pm 4$ & $1.5 \pm 0.1$ & $0.78 \pm 0.02$ & This work \\
\hline 46.9 Ptwt\% PtCoMn/HSC & 1 & 61 & 1.65 & 1.00 & This work \\
\hline 27.4 Ptwt $\% \mathrm{Pt}_{3} \mathrm{Co} / \mathrm{HSC}$ & 4 & $70 \pm 2$ & $2.17 \pm 0.06$ & $1.53 \pm 0.02$ & This work \\
\hline
\end{tabular}

Table 3. I/C dependence of SA and MA at $0.9 \mathrm{~V}$ vs. RHE for Pt based catalysts.

\begin{tabular}{|c|c|c|c|c|c|c|c|c|c|}
\hline \multirow{2}{*}{ Catalyst } & \multirow{2}{*}{$\begin{array}{c}\text { \# of } \\
\text { samples }\end{array}$} & \multicolumn{4}{|c|}{$\mathrm{SA}\left(\mathrm{mA} \cdot \mathrm{cm}^{-2} \mathrm{pt}\right)$} & \multicolumn{4}{|c|}{$\mathrm{MA}\left(\mathrm{mA} \cdot \mathrm{mg}^{-1} \mathrm{Pt}\right)$} \\
\hline & & $\mathrm{I} / \mathrm{C} 0$ & 0.5 & 1.5 & 3 & $\mathrm{I} / \mathrm{C} 0$ & 0.5 & 1.5 & 3 \\
\hline 26.1wt\% Pt/HSC & 4 & $\begin{array}{c}0.76 \pm \\
0.01\end{array}$ & $\begin{array}{c}0.65 \pm \\
0.04\end{array}$ & $\begin{array}{l}0.63 \pm \\
0.04\end{array}$ & $0.62 \pm 0.03$ & $\begin{array}{l}1.02 \pm \\
0.04\end{array}$ & $\begin{array}{c}0.86 \pm \\
0.05\end{array}$ & $\begin{array}{c}0.83 \pm \\
0.06\end{array}$ & $0.82 \pm 0.06$ \\
\hline 46.4wt\% Pt/HSC & 8 & $\begin{array}{l}0.87 \pm \\
0.08\end{array}$ & $\begin{array}{c}0.84 \pm \\
0.08\end{array}$ & $\begin{array}{l}0.77 \pm \\
0.09\end{array}$ & $0.64 \pm 0.04$ & $\begin{array}{l}0.84 \pm \\
0.07\end{array}$ & $\begin{array}{l}0.78 \pm \\
0.06\end{array}$ & $\begin{array}{l}0.71 \pm \\
0.08\end{array}$ & $0.57 \pm 0.03$ \\
\hline $29 w t \% \mathrm{Pt} / \mathrm{V}$ & 5 & $\begin{array}{l}1.01 \pm \\
0.07\end{array}$ & $\begin{array}{c}0.79 \pm \\
0.04\end{array}$ & $\begin{array}{l}0.59 \pm \\
0.03\end{array}$ & $0.51 \pm 0.03$ & $\begin{array}{l}0.94 \pm \\
0.07\end{array}$ & $\begin{array}{l}0.70 \pm \\
0.04\end{array}$ & $\begin{array}{c}0.52 \pm \\
0.04\end{array}$ & $0.43 \pm 0.03$ \\
\hline $46.4 \mathrm{wt} \% \mathrm{Pt} / \mathrm{V}$ & 2 & $\begin{array}{l}1.09 \pm \\
0.03\end{array}$ & $\begin{array}{c}0.82 \pm \\
0.08\end{array}$ & $\begin{array}{c}0.73 \pm \\
0.06\end{array}$ & $\begin{array}{c}0.656 \pm \\
0.007\end{array}$ & $\begin{array}{c}0.68 \pm \\
0.02\end{array}$ & $\begin{array}{c}0.48 \pm \\
0.06\end{array}$ & $\begin{array}{c}0.41 \pm \\
0.04\end{array}$ & $\begin{array}{c}0.346 \pm \\
0.001\end{array}$ \\
\hline $20 w t \% \mathrm{Pt} / \mathrm{LSC}$ & 1 & 1.12 & 0.55 & 0.48 & 0.44 & 0.76 & 0.35 & 0.30 & 0.27 \\
\hline 48wt\% Pt/LSC & 4 & $\begin{array}{l}1.81 \pm \\
0.04\end{array}$ & $\begin{array}{l}1.31 \pm \\
0.07\end{array}$ & $\begin{array}{l}0.83 \pm \\
0.05\end{array}$ & $0.68 \pm 0.03$ & $\begin{array}{c}0.87 \pm \\
0.02\end{array}$ & $\begin{array}{c}0.59 \pm \\
0.03\end{array}$ & $\begin{array}{c}0.36 \pm \\
0.03\end{array}$ & $0.68 \pm 0.01$ \\
\hline $\begin{array}{l}\text { 46.4 Ptwt } \% \\
\mathrm{Pt}_{3} \mathrm{Co} / \mathrm{HSC}\end{array}$ & 2 & $\begin{array}{l}1.50 \pm \\
0.03\end{array}$ & $\begin{array}{l}1.52 \pm \\
0.02\end{array}$ & $\begin{array}{l}1.50 \pm \\
0.01\end{array}$ & $1.41 \pm 0.02$ & $\begin{array}{l}0.97 \pm \\
0.02\end{array}$ & $\begin{array}{l}0.97 \pm \\
0.01\end{array}$ & $\begin{array}{l}0.95 \pm \\
0.01\end{array}$ & $0.91 \pm 0.01$ \\
\hline $\begin{array}{l}\text { 46.9 Ptwt\% } \\
\text { PtCoMn/HSC }\end{array}$ & 1 & 1.65 & 1.41 & 1.40 & 1.21 & 1.00 & 0.86 & 0.85 & 0.74 \\
\hline $\begin{array}{l}27.4 \text { Ptwt } \% \\
\mathrm{Pt}_{3} \mathrm{Co} / \mathrm{HSC}\end{array}$ & 1 & 2.10 & 2.01 & 1.78 & 1.69 & 1.55 & 1.39 & 1.27 & 1.25 \\
\hline
\end{tabular}


Error in SA and MA indicate standard deviation for catalysts tested using 4 or more samples, and maximum and minimum for catalysts tested using less than 4 samples.

To investigate the $\mathrm{SA}$ dependence on $\mathrm{I} / \mathrm{C}$ ratio further, the $\mathrm{SA}$ values were normalized using the value at I/C $\sim 0$ for each catalyst as shown in Fig. 4. The rate at which the SA decreases is high at low $\mathrm{I} / \mathrm{C}$ ratios $<1.5$ and approaches zero at $\mathrm{I} / \mathrm{C}$ ratios $>1.5$. For $46 \mathrm{wt} \% \mathrm{Pt} / \mathrm{HSC}$, such trend is not clearly observed. This may be due to insufficient penetration of Nafion through thickness direction of catalyst layer. The SA loss at high I/C ratios shows the following trend: HSC $<$ Vulcan $<$ LSC. In contrast, no clear trend is observed within catalysts with similar average particle size/ECA ( 97 $\mathrm{m}^{2} \cdot \mathrm{g}_{\mathrm{Pt}}{ }^{-1}: 46 \mathrm{wt} \% \mathrm{Pt} / \mathrm{HSC}$ vs. $29 \mathrm{wt} \% \mathrm{Pt} / \mathrm{V}, \sim 65 \mathrm{~m}^{2} \cdot \mathrm{g}_{\mathrm{Pt}}{ }^{-1}: 46 \mathrm{wt} \% \mathrm{Pt} / \mathrm{V}$ vs. $20 \mathrm{wt} \%$ Pt/LSC). Thus, properties of carbon, coverage or thickness of Nafion are likely to be dominant factors that determine the extent of the SA loss. 


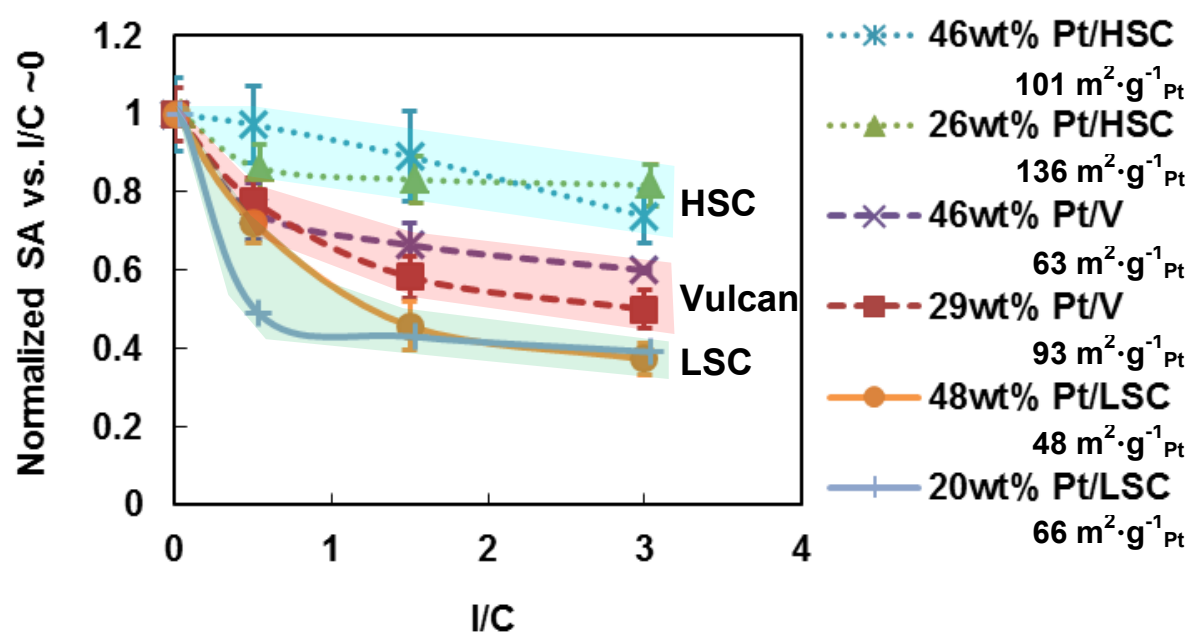

Figure 4. I/C ratio dependence of normalized SA for various $\mathrm{Pt} / \mathrm{C}$ catalysts. SA at $0.9 \mathrm{~V}$ normalized to Nafion-free surface of each Pt/C catalyst. Error bars indicate normalized standard deviation for catalysts tested using 4 or more samples (46 wt $\%$ and $26 \mathrm{wt} \%$ $\mathrm{Pt} / \mathrm{HSC}, 29 \mathrm{wt} \% \mathrm{Pt} / \mathrm{V}$ and $48 \mathrm{wt} \% \mathrm{Pt} / \mathrm{LSC}$ ), and normalized maximum and minimum SA for catalysts tested using less than 4 samples ( $46 \mathrm{wt} \% \mathrm{Pt} / \mathrm{V})$.

In an attempt to investigate the factors, we estimated carbon-surface-area-specific Nafion loading from I/C ratio and BET surface area of carbon supports: HSC, Vulcan $\sim 250 \mathrm{~m}^{2} \cdot \mathrm{g}^{-1}$, LSC $\sim 80 \mathrm{~m}^{2} \cdot \mathrm{g}^{-1}$ and replotted SA in relation to the Nafion loading (Fig. 5). The SA dependence for poly-Pt is also plotted in Fig. 5. In addition, Nafion film thickness was estimated assuming uniform coverage using the BET surface areas (Fig. 5, second abscissa). We note that BET surface area of HSC support is assumed to be the same as Vulcan support (although the actual BET surface area is $\sim 800 \mathrm{~m}^{2} \cdot \mathrm{g}^{-1}$ ) because 
of similar carbon particle sizes for HSC and Vulcan, and the following understanding reported in literature: i) Pt particles are located both on the outer surface of HSC particles and within pores of the HSC [36, 38, 39], and ii) Pt particles located on the outer surface of the HSC support are in touch with ionomer whereas those located within pores of the HSC support are not [37-39]. Pt/Vulcan and Pt/LSC catalysts exhibit similarly large SA loss with increasing Nafion loadings/thickness to $\sim 1 \mu \mathrm{g} \cdot \mathrm{cm}^{-2}$ carbon $/ \sim 5$ nm followed by plateau (red band) whereas Pt/HSC catalysts show relatively small SA loss by the plateau. It is noteworthy that Nafion thickness where the normalized SA starts to plateau $(\sim 5 \mathrm{~nm})$ coincides with the reported minimum Nafion thickness [40]. Although researchers have assumed simplified model with thin uniform $\sim 2 \mathrm{~nm}$ Nafion film covering the entire catalyst surface, recent microscopic study demonstrated that Nafion forms finite-sized layer and covers carbon support non-uniformly with a minimum thickness $\sim 5 \mathrm{~nm}$ and Nafion coverage becomes higher with increasing Nafion loadings [40]. This study indicates that, in Fig.5, Nafion coverage becomes lower at the loadings less than $\sim 1 \mu \mathrm{g} \cdot \mathrm{cm}^{-2}$ carbon $(<\sim 5 \mathrm{~nm}$ in thickness $)$ and it can reach unity at the loadings more than that. Because the SA decreases in the loading range where the coverage increases and it starts to plateau at the loading where the coverage becomes close to unity, it is plausible to consider that Nafion coverage is a dominant factor that 
controls the SA loss on Pt catalysts. Comparable normalized SA values for Nafion-capped poly-Pt (coverage 1) [17], Pt/Vulcan and Pt/LSC in the plateau region are consistent with the interpretation. Thus, it is reasonable to conclude that the attenuated SA loss for Pt/HSC catalysts in the plateau region is because Pt particles that are sheltered from Nafion in micropores of HSC support maintain their original activity [37-39]. The differences in the rate of SA loss observed between $46 \mathrm{wt} \%$ and $26 \mathrm{wt} \%$ Pt/HSC catalysts and between $48 \mathrm{wt} \%$ and $20 \mathrm{wt} \%$ Pt/LSC catalysts may have been caused by variation in the extent of Nafion penetration. Further studies such as the observation of sulfonate adsorption using so-called CO displacement method $[13,18]$ are necessary to understand the Nafion loading dependence on SA in more details.

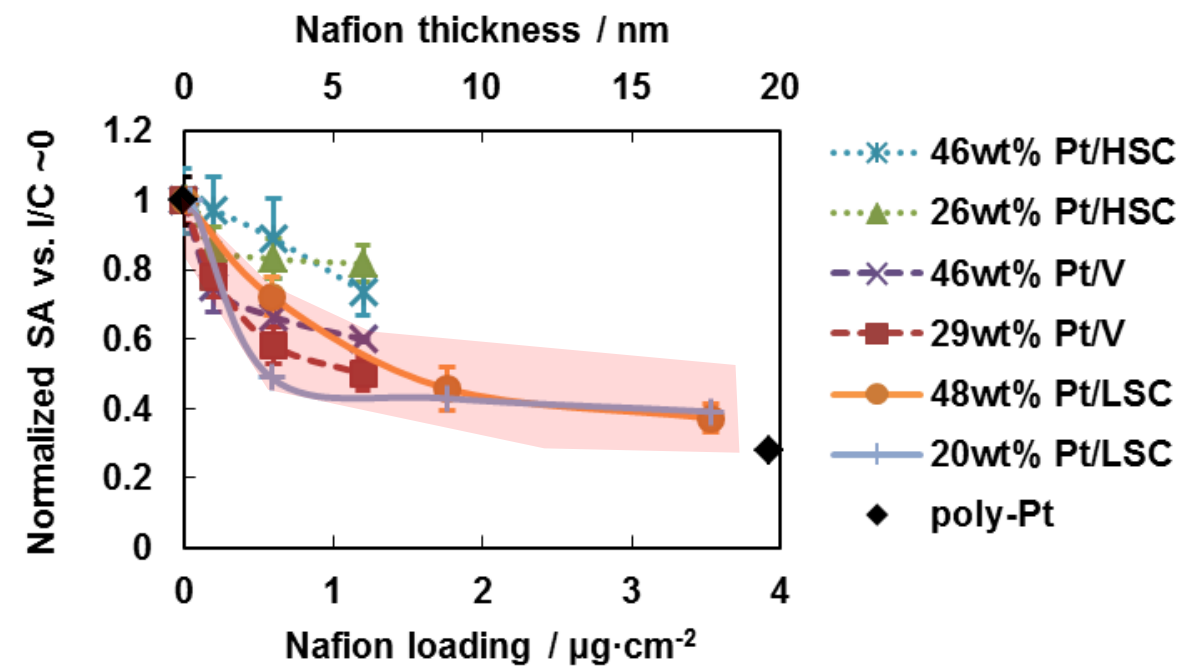

Figure 5. Nafion loading dependence of the normalized $\mathrm{SA}$ at $0.9 \mathrm{~V}$ for $\mathrm{Pt} / \mathrm{C}$ nanoparticle catalysts as well as bulk poly-Pt. Nafion loading/thickness estimated from 
actual roughness factor for poly-Pt. Error bars indicate normalized standard deviation for catalysts tested using 4 or more samples (46 wt\% and $26 \mathrm{wt} \% \mathrm{Pt} / \mathrm{HSC}, 29 \mathrm{wt} \% \mathrm{Pt} / \mathrm{V}$ and $48 \mathrm{wt} \% \mathrm{Pt} / \mathrm{LSC}$ ), and normalized maximum and minimum SA for catalysts tested using less than 4 samples (46 wt\% Pt/V).

The SA dependence on $\mathrm{I} / \mathrm{C}$ ratio for $\mathrm{Pt} / \mathrm{HSC}$ and Pt-alloy/HSC catalysts is summarized in Fig. 6a and can also be found in Table 3. At I/C 0, Pt-alloy/HSC catalysts exhibit $\sim 1.7$ to $\sim 2.9$ times higher SA values than Pt/HSC (Table 2); the higher SA values of Pt-alloy/HSC catalysts are likely due to combined effects from alloying and larger particle size. As is observed for Pt/HSC catalysts, Nafion also lowers the SA of Pt-alloy/HSC catalysts. In normalized SA scale (Fig. 6b), similar I/C dependence is observed although there is some variation among Pt alloy catalysts. Although the relatively small SA loss for $46 \mathrm{wt} \% \mathrm{Pt}_{3} \mathrm{Co} / \mathrm{HSC}$ may indicate that the impact of Nafion also depends on metallic composition of catalysts, further studies need to be conducted e.g. by employing catalysts supported on Vulcan or LSC. 

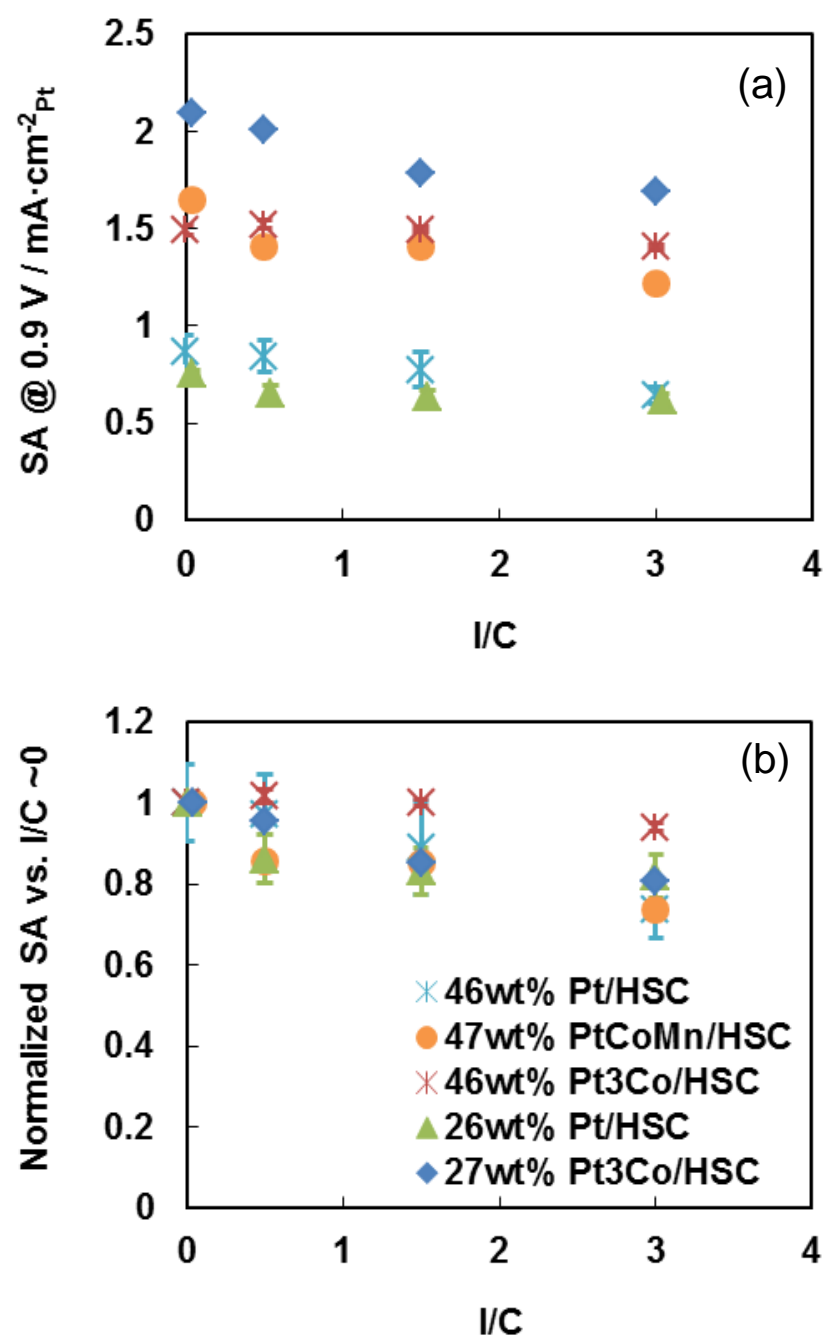

Figure 6. The dependences of (a) SA and (b) normalized SA to SA for Nafion-free surface of each catalyst on I/C ratio for HSC supported Pt-based catalysts. Error bars indicate standard deviation for $26 \mathrm{wt} \%$ and $46 \mathrm{wt} \% \mathrm{Pt} / \mathrm{HSC}$ obtained for 4 and 8 samples, respectively, and maximum and minimum for $46 \mathrm{wt} \% \mathrm{Pt}_{3} \mathrm{Co} / \mathrm{HSC}$ obtained for 2 samples. 


\subsection{Implications for MEAs}

In automotive PEMFCs, membrane electrode assembly must function from low to high relative humidity $(\mathrm{RH})$ at various temperatures. At low $\mathrm{RH}$ conditions, proton conduction to Pt surfaces can be significantly perturbed without being in touch with ionomer. For Pt/HSC catalyst layers with typically used compositions, Pt utilization defined as the ratio of electrochemical area to the total surface area can become as low as $\sim 30 \%$ at low $\mathrm{RH}$ conditions while the utilization is as high as $\sim 90 \%$ at high $\mathrm{RH}$ conditions [37-39]. The lowered utilization due to lower ionomer coverage can lower the ORR current. Our study, however, indicates that higher Nafion coverage on Pt and Pt alloy catalyst surfaces results in lower ORR activity. Furthermore, ionomer poisoning may become more deleterious at lower $\mathrm{RH}$ conditions; onset potential of oxide formation/desorption currents positively shifts to a great extent at lower RH conditions $[39,41]$. Therefore, further study with this type of support structure may provide an improved PEMFC performance.

\section{Conclusion}

The effect of Nafion on the ORR activity was studied for Pt/C and Pt-alloy/C catalysts using thin-film RDE methods in $0.1 \mathrm{M} \mathrm{HClO}_{4}$. In order to determine the impact of 
Nafion on the ORR kinetics, mass transport limitation within catalyst layers was minimized by employing ultrathin-uniform catalyst layers. In addition, standardized activity measurement protocols were applied to obtain accurate and reproducible ORR activity. It was found that Nafion lowered the ORR activity and the SA decrease plateaued with increasing Nafion loadings for most catalysts. Analysis in normalized SA scale to corresponding Nafion-free surface suggests that Nafion coverage is a dominant factor that determines the extent of the SA decrease on Pt surfaces, and Pt particle size was found not to have significant influence on the extent of the SA decrease upon Nafion incorporation. Further studies need to be conducted to determine the influence of metallic composition of catalysts on the impact of Nafion loading on SA. Catalysts using HSC support exhibited attenuated SA loss at Nafion loadings where the SA plateaued. This attenuated loss is the result of the combination of original activity on Nafion-free Pt catalysts located within pores of HSC particles and lowered activity on Nafion-covered Pt catalysts located on the outer surface of the HSC particles. Because catalysts using HSC support lose some electrochemical area at low RH in PEMFCs, HSC support may not be an ideal from this aspect. However, our study also suggests that HSC support can maintain original Pt activity by sheltering $\mathrm{Pt}$ 
particles in micropores from ionomer coverage. Thus, further study with this type of support structure may improve PEMFC performance.

\section{Acknowledgement}

Shyam S. Kocha gratefully acknowledges funding from the U.S. Department of Energy, Fuel Cells Technologies Program under Contract No. DE-AC36-08-GO28308 to the National Renewable Energy Laboratory. Kazuma Shinozaki's stay at NREL and CSM was funded by Toyota Central R\&D Labs., Inc. We would like to acknowledge Umicore for providing their catalysts. 


\section{References}

[1] D. Papageorgopoulos, Fuel Cells Overview, Annual Merit Review Proceedings Fuel Cells, (2014).

[2] S.S. Kocha, Electrochemical Degradation : Electrocatalyst and Support Durability, in: M. Mench, E.C. Kumbur, T.N. Veziroglu (Eds.) Polymer Electrolyte Fuel Cell Degradation, Elsevier Inc., 2012, pp. 89-214.

[3] A. Iiyama, K. Shinohara, S. Iguchi, A. Daimaru, in: W. Vielstich, H.A. Gasteiger, H. Yokokawa (Eds.) Handbook of Fuel Cells: Advances in Electrocatalysis, Materials, Diagnostics and Durability, Wiley, Chichester, UK, 2009, pp. 1090.

[4] S.S. Kocha, Principles of MEA preparation, in: W. Lamm, V. Arnold, H.A. Gasteiger (Eds.) Handbook of Fuel Cells - Fundamentals, Technology and Applications, John Wiley \& Sons, Ltd, Chichester, UK, 2003, pp. 538-565.

[5] Y. Ono, T. Mashio, S. Takaichi, A. Ohma, H. Kanesaka, K. Shinohara, The analysis of performance loss with low platinum loaded cathode catalyst layers, ECS Transactions, 28 (2010) 69.

[6] N. Nonoyama, S. Okazaki, A.Z. Weber, Y. Ikogi, T. Yoshida, Analysis of Oxygen-Transport Diffusion Resistance in Proton-Exchange-Membrane Fuel Cells, Journal of The Electrochemical Society, 158 (2011) B416.

[7] A. Ohma, T. Mashio, K. Sato, H. Iden, Y. Ono, K. Sakai, K. Akizuki, S. Takaichi, K. Shinohara, Analysis of proton exchange membrane fuel cell catalyst layers for reduction of platinum loading at Nissan, Electrochimica Acta, 56 (2011) 10832.

[8] S. Jomori, N. Nonoyama, T. Yoshida, Analysis and modeling of PEMFC degradation: Effect on oxygen transport, Journal of Power Sources, 215 (2012) 18.

[9] T. Suzuki, K. Kudo, Y. Morimoto, Model for investigation of oxygen transport limitation in a polymer electrolyte fuel cell, Journal of Power Sources, 222 (2013) 379. [10] J.P. Owejan, J.E. Owejan, W. Gu, Impact of Platinum Loading and Catalyst Layer Structure on PEMFC Performance, Journal of the Electrochemical Society, 160 (2013) F824.

[11] R. Jinnouchi, K. Kudo, N. Kitano, Y. Morimoto, Molecular Dynamics Simulations on O2 Permeation through Nafion Ionomer on Platinum Surface, Electrochimica Acta, 188 (2016) 767.

[12] K. Kudo, R. Jinnouchi, Y. Morimoto, Humidity and Temperature Dependences of Oxygen Transport Resistance 
of Nafion Thin Film on Platinum Electrode, Electrochimica Acta, (2016) in press.

[13] R. Subbaraman, D. Strmcnik, V. Stamenkovic, N.M. Markovic, Three Phase Interfaces at Electrified Metal-Solid Electrolyte Systems 1. Study of the Pt( hkl )-Nafion Interface, The Journal of Physical Chemistry C, 114 (2010) 8414.

[14] R. Subbaraman, D. Strmcnik, A.P. Paulikas, V.R. Stamenkovic, N.M. Markovic, Oxygen reduction reaction at three-phase interfaces., ChemPhysChem : A European journal of chemical physics and physical chemistry, 11 (2010) 2825.

[15] A.M. Gómez-Marín, A. Berná, J.M. Feliu, Spectroelectrochemical Studies of the Pt(111)/Nafion Interface Cast Electrode, The Journal of Physical Chemistry C, 114 (2010) 20130.

[16] M. Ahmed, D. Morgan, G.A. Attard, E. Wright, D. Thompsett, J. Sharman, Unprecedented Structural Sensitivity toward Average Terrace Width: Nafion Adsorption at Pt $\{$ hkl $\}$ Electrodes, The Journal of Physical Chemistry C, 115 (2011) 17020.

[17] K. Kodama, A. Shinohara, N. Hasegawa, K. Shinozaki, R. Jinnouchi, T. Suzuki, T. Hatanaka, Y. Morimoto, Catalyst Poisoning Property of Sulfonimide Acid Ionomer on Pt (111) Surface, Journal of the Electrochemical Society, 161 (2014) F649.

[18] J. Clavilier, R. Albalat, R. Gomez, J.M. Orts, J.M. Feliu, A. Aldaz, Study of the charge displacement at constant potential during $\mathrm{CO}$ adsorption on $\mathrm{Pt}(110)$ and $\mathrm{Pt}(111)$ electrodes in contact with a perchloric acid solution, Journal of Electroanalytical Chemistry, 330 (1992) 489-497.

[19] E. Higuchi, H. Uchida, M. Watanabe, Effect of loading level in platinum-dispersed carbon black electrocatalysts on oxygen reduction activity evaluated by rotating disk electrode, Journal of Electroanalytical Chemistry, 583 (2005) 69.

[20] O.J. Curnick, B.G. Pollet, P.M. Mendes, Nafion®-stabilised Pt/C electrocatalysts with efficient catalyst layer ionomer distribution for proton exchange membrane fuel cells, RSC Advances, 2 (2012) 8368.

[21] J. Speder, L. Altmann, M. Roefzaad, M. Bäumer, J.J.K. Kirkensgaard, K. Mortensen, M. Arenz, Pt based PEMFC catalysts prepared from colloidal particle suspensions--a toolbox for model studies., Physical chemistry chemical physics : PCCP, 15 (2013) 3602.

[22] E. Guilminot, A. Corcella, M. Chatenet, F. Maillard, Comparing the thin-film rotating disk electrode and the ultramicroelectrode with cavity techniques to study carbon-supported platinum for proton exchange membrane fuel cell applications, Journal of Electroanalytical Chemistry, 599 (2007) 111. 
[23] T.J. Schmidt, H.A. Gasteiger, G.D. Stab, D.M. Kolb, R.J. Behm, Characterization of High-Surface-Area Electrocatalysts Using a Rotating Disk Electrode Configuration, Journal of The Electrochemical Society, 145 (1998) 2354.

[24] K. Shinozaki, J.W. Zack, S. Pylypenko, B.S. Pivovar, S.S. Kocha, Oxygen Reduction Reaction Measurements on Platinum Electrocatalysts Utilizing Rotating Disk Electrode Technique, Journal of The Electrochemical Society, 162 (2015) F1384.

[25] K. Shinozaki, J.W. Zack, R.M. Richards, B.S. Pivovar, S.S. Kocha, Oxygen Reduction Reaction Measurements on Platinum Electrocatalysts Utilizing Rotating Disk Electrode Technique: I. Impact of Impurities, Measurement Protocols and Applied Corrections, Journal of The Electrochemical Society, 162 (2015) F1144.

[26] K. Shinozaki, J.W. Zack, S. Pylypenko, R.M. Richards, B.S. Pivovar, S.S. Kocha, Benchmarking the oxygen reduction reaction activity of Pt-based catalysts using standardized rotating disk electrode methods, International Journal of Hydrogen Energy, 40 (2015) 16820.

[27] S. Gilman, A STUDY OF THE MECHANISM OF CARBON MONOXIDE ADSORPTION ON PLATINUM BY A NEW ELECTROCHEMICAL PROCEDURE 1, The Journal of Physical Chemistry, 67 (1963) 78.

[28] S. Gilman, Measurement of hydrogen adsorption by the multipulse potentiodynamic (mpp) method, Journal of Electroanalytical Chemistry (1959), 7 (1964) 382.

[29] S.B. Brummer, The Use of Large Anodic Galvanostatic Transients to Evaluate the Maximum Adsorption on Platinum from Formic Acid Solutions, The Journal of Physical Chemistry, 69 (1965) 562.

[30] T. Biegler, R. Woods, Limiting oxygen coverage on smooth platinum anodes in acid solution, Journal of Electroanalytical Chemistry and Interfacial Electrochemistry, 20 (1969) 73.

[31] K. Shinozaki, Y. Morimoto, B.S. Pivovar, S.S. Kocha, Re-examination of the Pt Particle Size Effect on the ORR for Nafion-Free Ultrathin Uniform Pt/C Catalyst Layers, Electrochimica Acta, (2016) submitted.

[32] Y. Garsany, O.A. Baturina, K.E. Swider-Lyons, S.S. Kocha, Experimental methods for quantifying the activity of platinum electrocatalysts for the oxygen reduction reaction, Analytical Chemistry, 82 (2010) 6321.

[33] D. Chu, D. Tryk, D. Gervasio, E.B. Yeager, Examination of the ionomer/electrode interface using the ferric/ferrous redox couple, Journal of Electroanalytical Chemistry and Interfacial Electrochemistry, 272 (1989) 277. 
[34] A. Ohma, K. Fushinobu, K. Okazaki, Influence of Nafion® ${ }^{\circledR}$ film on oxygen reduction reaction and hydrogen peroxide formation on $\mathrm{Pt}$ electrode for proton exchange membrane fuel cell, Electrochimica Acta, 55 (2010) 8829.

[35] J. Maruyama, M. Inaba, K. Katakura, Z. Ogumi, Z.-i. Takehara, Influence of Nafion ${ }^{\circledR}$ film on the kinetics of anodic hydrogen oxidation, Journal of Electroanalytical Chemistry, 447 (1998) 201.

[36] H. Jinnai, R.J. Spontak, T. Nishi, Transmission Electron Microtomography and Polymer Nanostructures, Macromolecules, 43 (2010) 1675.

[37] K. Ikeda, N. Nonoyama, Y. Ikogi, Analysis of the ionomer coverage of Pt surface in PEMFC, ECS Transactions, 33 (2010) 1189.

[38] K. Shinozaki, H. Yamada, Y. Morimoto, Relative Humidity Dependence of Pt Utilization in Polymer Electrolyte Fuel Cell Electrodes: Effects of Electrode Thickness, Ionomer-to-Carbon Ratio, Ionomer Equivalent Weight, and Carbon Support, Journal of The Electrochemical Society, 158 (2011) B467.

[39] H. Iden, A. Ohma, An in situ technique for analyzing ionomer coverage in catalyst layers, Journal of Electroanalytical Chemistry, 693 (2013) 34.

[40] M. Lopez-Haro, L. Guétaz, T. Printemps, A. Morin, S. Escribano, P.-H. Jouneau, P. Bayle-Guillemaud, F. Chandezon, G. Gebel, Three-dimensional analysis of Nafion layers in fuel cell electrodes., Nature communications, 5 (2014) 5229.

[41] K. Kodama, R. Jinnouchi, T. Suzuki, H. Murata, T. Hatanaka, Y. Morimoto, Increase in adsorptivity of sulfonate anions on Pt (111) surface with drying of ionomer, Electrochemistry Communications, 36 (2013) 26. 

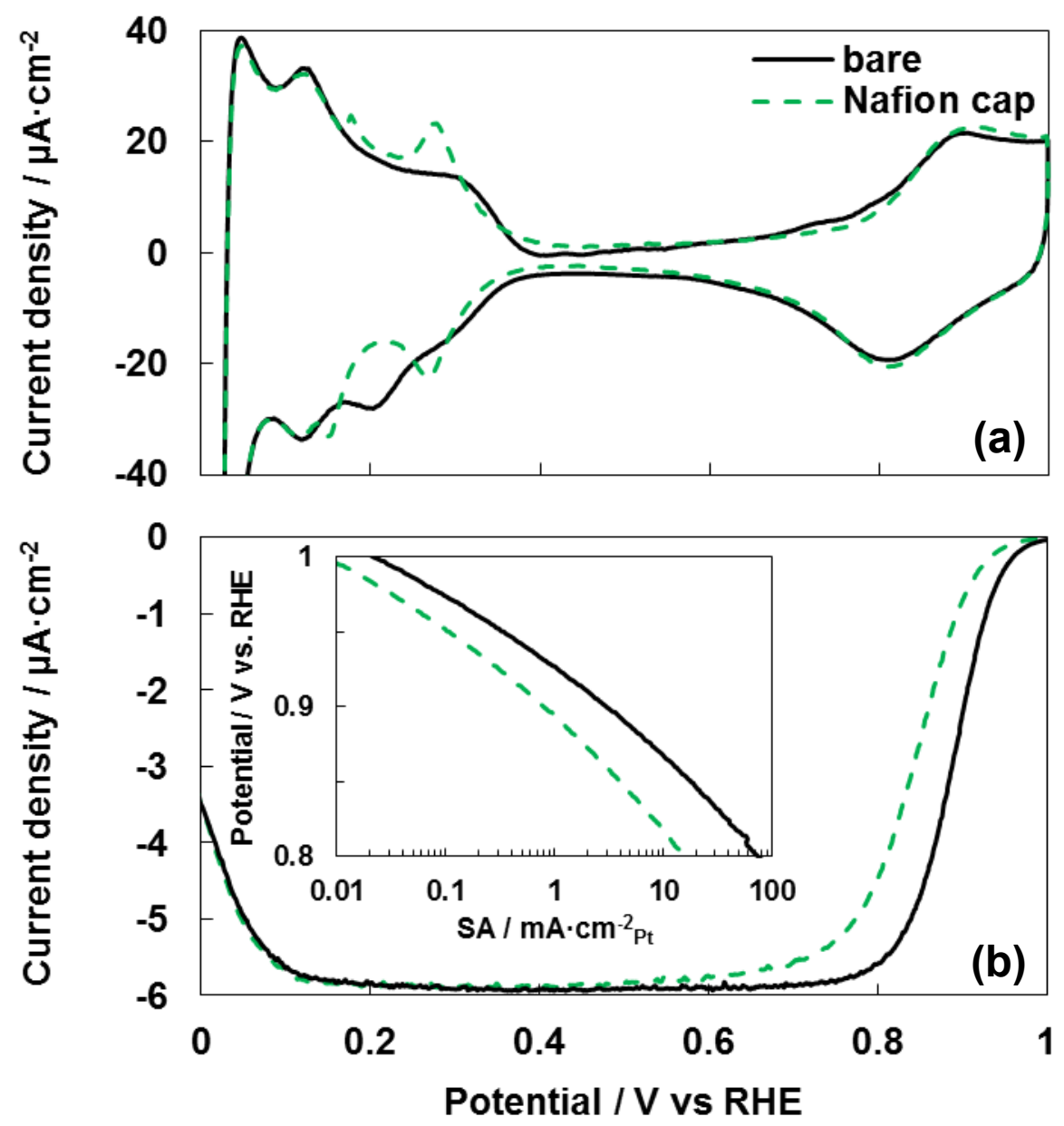

Figure 1 

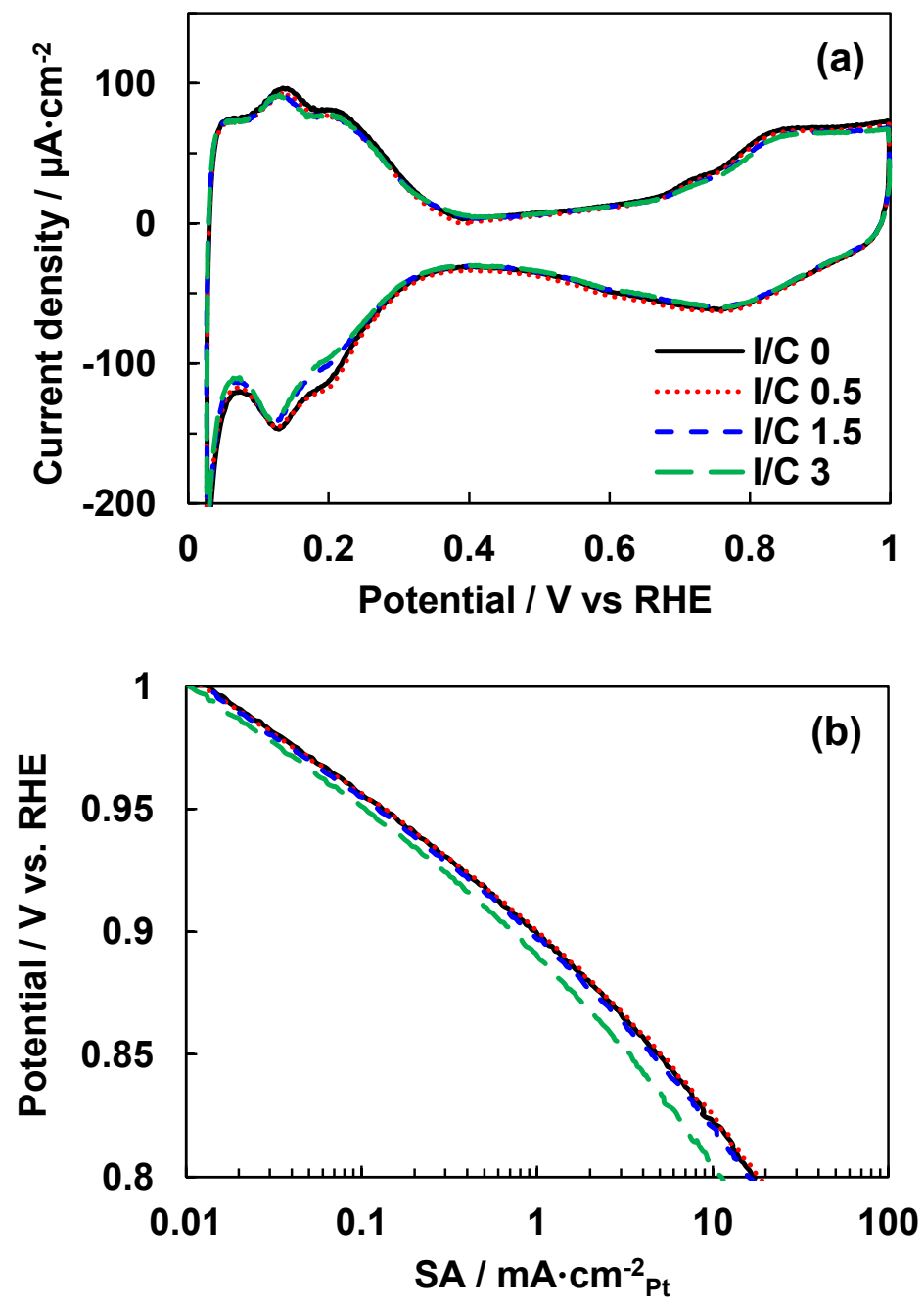

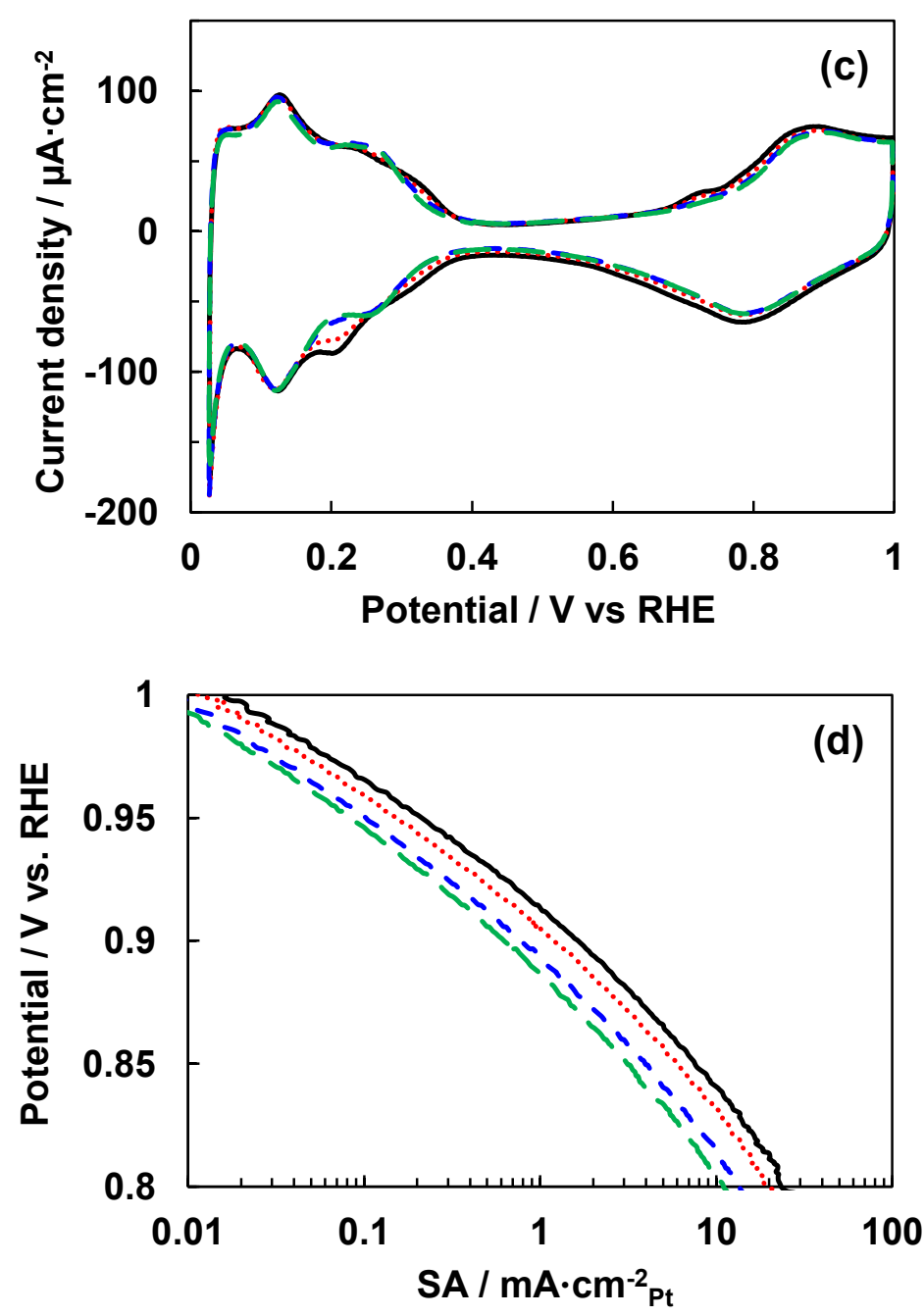

Figure 2 
Figure 3

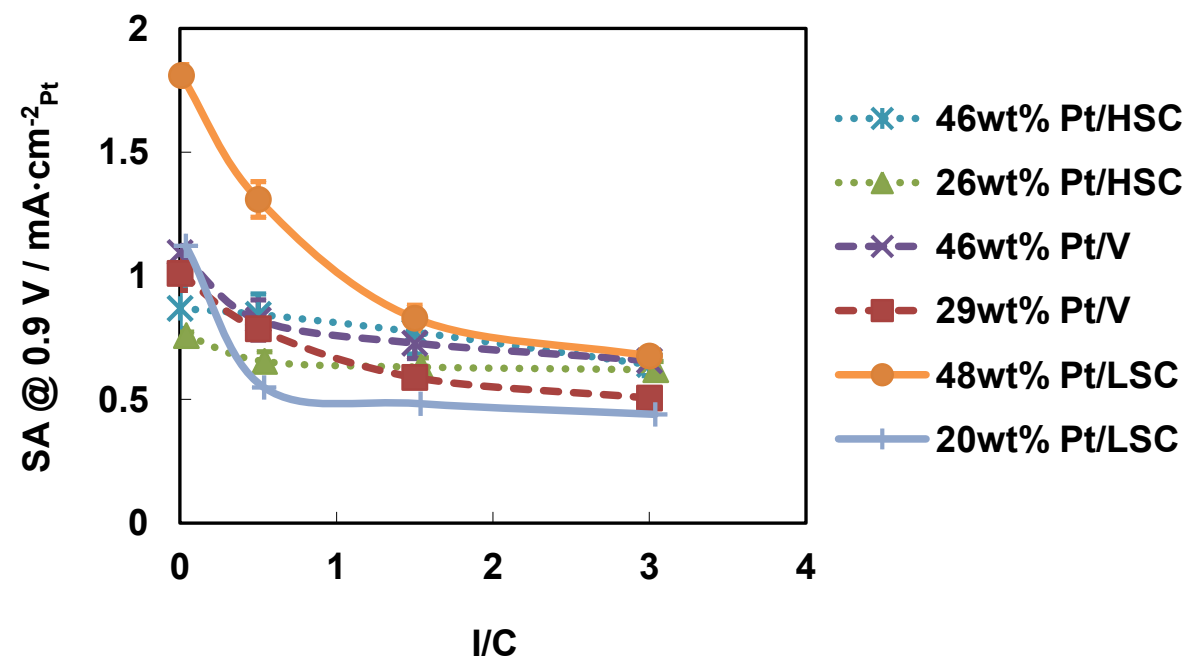

Figure 3 


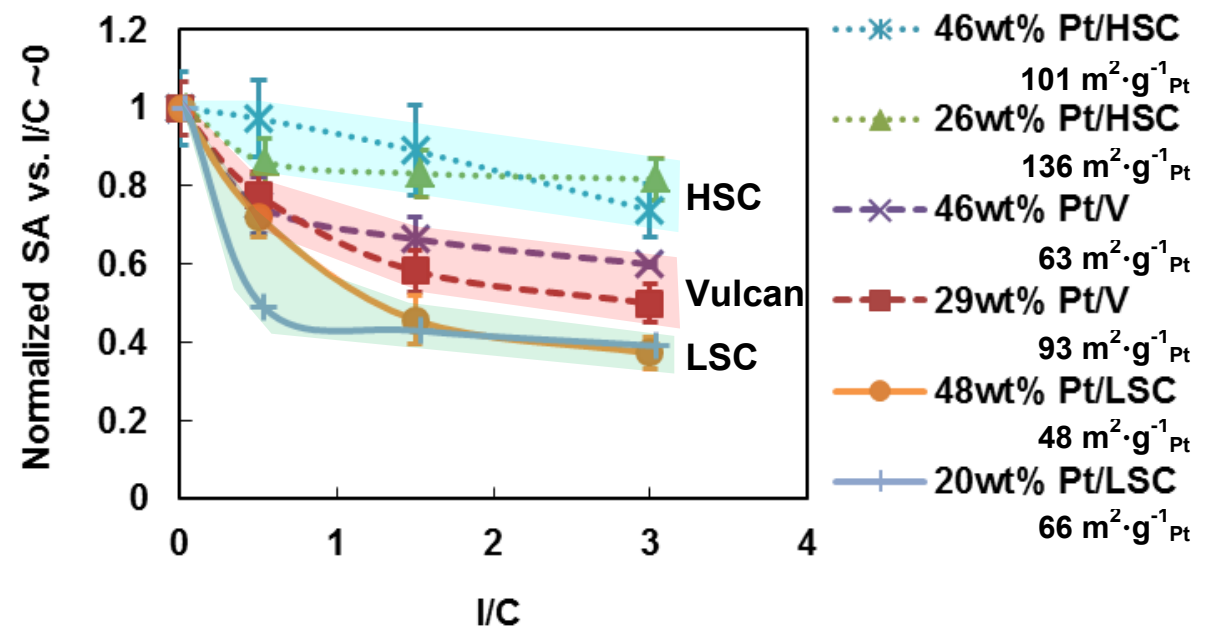

Figure 4 
Figure 5

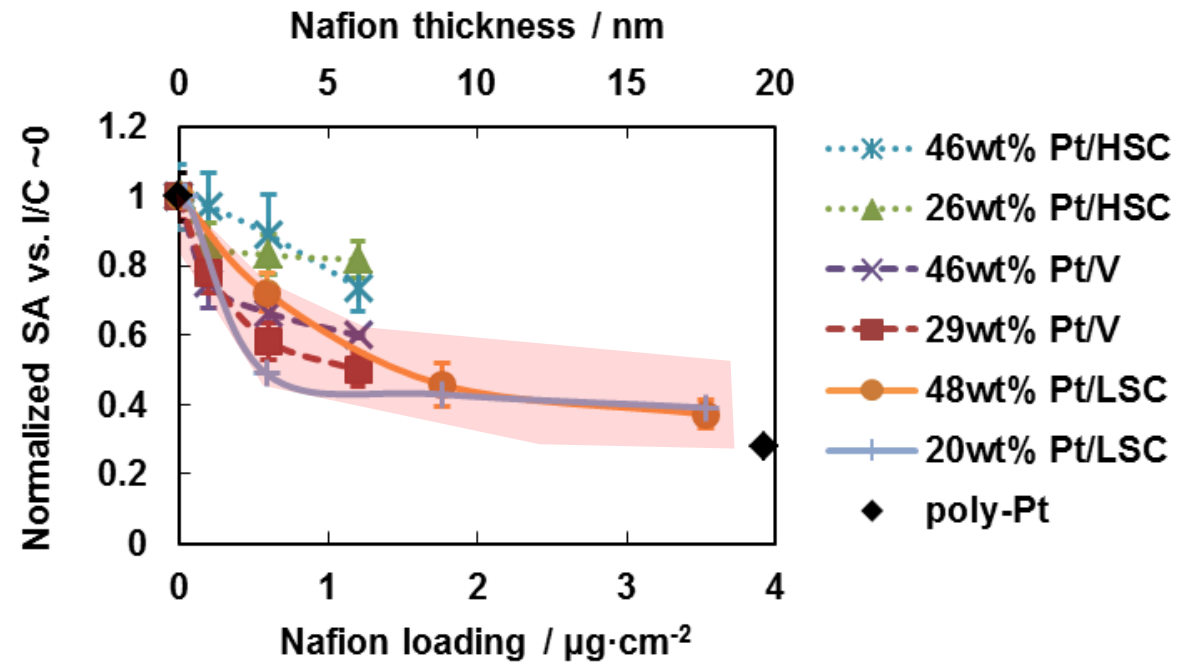

Figure 5 
Figure 6
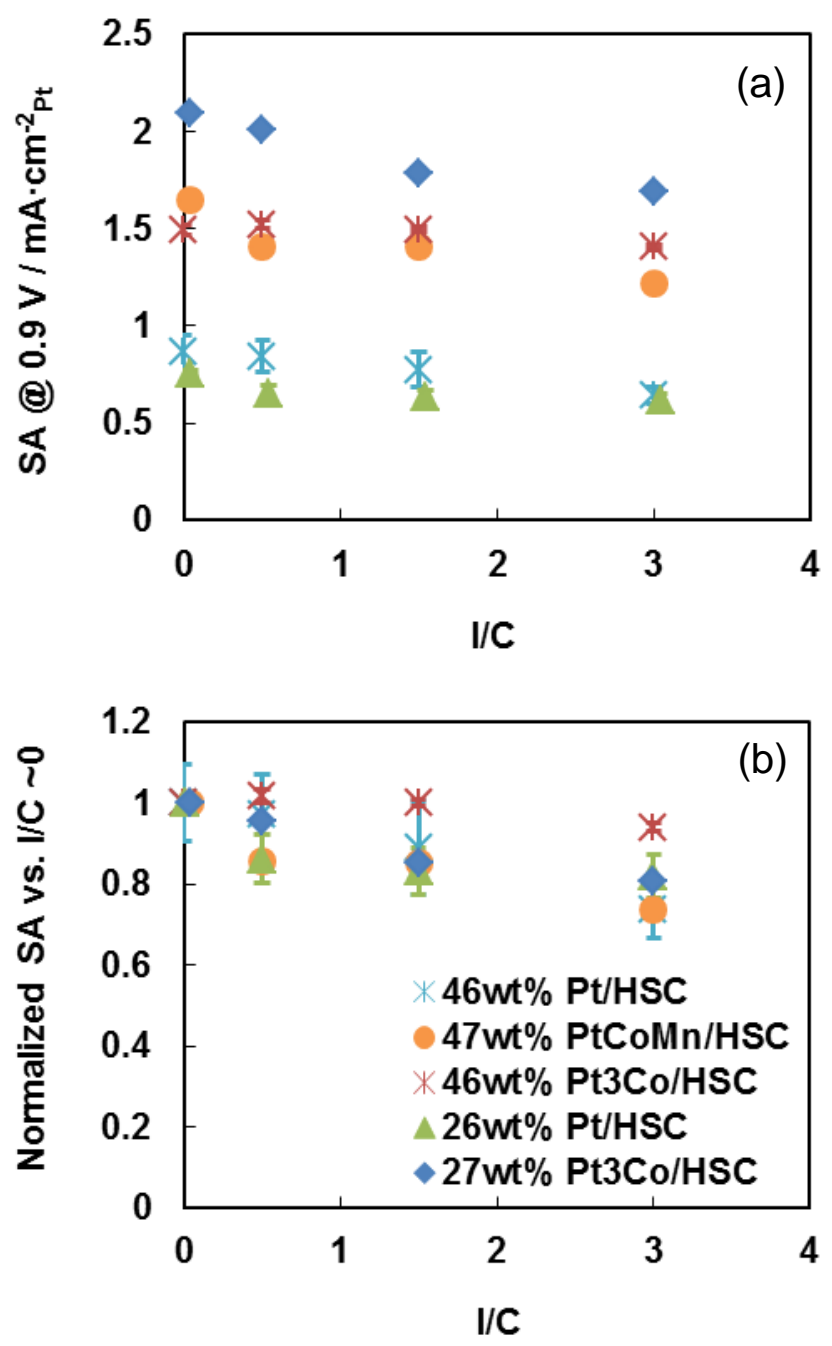

Figure 6 
Figure 1. (a) CVs under $\mathrm{N}_{2}$ and (b) ORR I-E curves (inset: Tafel plot) in $0.1 \mathrm{M} \mathrm{HClO}_{4}$ at $20 \mathrm{mV} \cdot \mathrm{s}^{-1}$ for poly-Pt with and without Nafion cap.

Figure 2. The effect of I/C ratio on (a, c) CVs under $\mathrm{N}_{2}$ and (b, d) ORR I-E curves in 0.1 $\mathrm{M} \mathrm{HClO}_{4}$ at $20 \mathrm{mV} \cdot \mathrm{s}^{-1}$ for (a, b) $46 \mathrm{wt} \% \mathrm{Pt} / \mathrm{HSC}$ and (c, d) $48 \mathrm{wt} \% \mathrm{Pt} / \mathrm{LSC}$.

Figure 3. I/C ratio dependence of $\mathrm{SA}$ at $0.9 \mathrm{~V}$ for various $\mathrm{Pt} / \mathrm{C}$ catalysts. Error bars indicate standard deviation for catalysts tested using 4 or more samples (46 wt $\%$ and 26 wt $\% \mathrm{Pt} / \mathrm{HSC}, 29 \mathrm{wt} \% \mathrm{Pt} / \mathrm{V}$ and $48 \mathrm{wt} \% \mathrm{Pt} / \mathrm{LSC})$, and maximum and minimum for catalysts tested using less than 4 samples (46 wt $\% \mathrm{Pt} / \mathrm{V})$.

Figure 4. I/C ratio dependence of normalized SA for various $\mathrm{Pt} / \mathrm{C}$ catalysts. SA at $0.9 \mathrm{~V}$ normalized to Nafion-free surface of each Pt/C catalyst. Error bars indicate normalized standard deviation for catalysts tested using 4 or more samples (46 wt $\%$ and $26 \mathrm{wt} \%$ Pt/HSC, $29 \mathrm{wt} \% \mathrm{Pt} / \mathrm{V}$ and $48 \mathrm{wt} \% \mathrm{Pt} / \mathrm{LSC})$, and normalized maximum and minimum SA for catalysts tested using less than 4 samples (46 wt\% Pt/V). 
Figure 5. Nafion loading dependence of the normalized SA at $0.9 \mathrm{~V}$ for $\mathrm{Pt} / \mathrm{C}$ nanoparticle catalysts as well as bulk poly-Pt. Nafion loading/thickness estimated from actual roughness factor for poly-Pt. Error bars indicate normalized standard deviation for catalysts tested using 4 or more samples (46 wt $\%$ and $26 \mathrm{wt} \% \mathrm{Pt} / \mathrm{HSC}, 29 \mathrm{wt} \% \mathrm{Pt} / \mathrm{V}$ and $48 \mathrm{wt} \% \mathrm{Pt} / \mathrm{LSC}$ ), and normalized maximum and minimum SA for catalysts tested using less than 4 samples (46 wt\% Pt/V).

Figure 6. The dependences of (a) SA and (b) normalized SA to SA for Nafion-free surface of each catalyst on I/C ratio for HSC supported Pt-based catalysts. Error bars indicate standard deviation for $26 \mathrm{wt} \%$ and $46 \mathrm{wt} \% \mathrm{Pt} / \mathrm{HSC}$ obtained for 4 and 8 samples, respectively, and maximum and minimum for $46 \mathrm{wt} \% \mathrm{Pt}_{3} \mathrm{Co} / \mathrm{HSC}$ obtained for 2 samples. 